\title{
Animal Models of SARS-CoV-2: A Systematic Review
}

Prabudh Goel*, Vishesh Jain, Anjan Kumar Dhua, Devendra Kumar Yadav, Ajay

Verma, Aparajita Mitra, Tripti Khanna, Sandeep Agarwala, Minu Bajpai

[Department of Pediatric Surgery, All India Institute of Medical Sciences, New Delhi]

\section{Affiliations:}

1. Prabudh Goel: Associate Professor of Pediatric Surgery, All India Institute of Medical Sciences, New Delhi, India. PIN 110029.

2. Vishesh Jain: Associate Professor of Pediatric Surgery, All India Institute of Medical Sciences, New Delhi, India. PIN 110029.

3. Anjan Kumar Dhua: Associate Professor of Pediatric Surgery, All India Institute of Medical Sciences, New Delhi, India. PIN 110029.

4. Devendra Kumar Yadav: Associate Professor of Pediatric Surgery, All India Institute of Medical Sciences, New Delhi, India. PIN 110029.

5. Ajay Verma: Assistant Professor of Pediatric Surgery, All India Institute of Medical Sciences, New Delhi, India. PIN 110029.

6. Aparajita Mitra: Assistant Professor of Pediatric Surgery, All India Institute of Medical Sciences, New Delhi, India. PIN 110029.

7. Tripti Khanna: Scientist G, Division of Non-Communicable Diseases, Indian Council of Medical Research, New Delhi, India. PIN 110029.

8. Sandeep Agarwala: Professor of Pediatric Surgery, All India Institute of Medical Sciences, New Delhi, India. PIN 110029.

9. Minu Bajpai: Professor of Pediatric Surgery, All India Institute of Medical Sciences, New Delhi, India. PIN 110029.

\author{
Corresponding Author \\ Dr. Prabudh Goel \\ Associate Professor of Paediatric Surgery \\ All India Institute of Medical Sciences, New Delhi, India.
}

\author{
Address for Correspondence \\ Dr. Prabudh Goel \\ Associate Professor of Paediatric Surgery \\ Room No. 4002, $4^{\text {th }}$ Floor, Teaching Block, \\ All India Institute of Medical Sciences, New Delhi, India. PIN 110029 \\ Phone: +91-9999944511 \\ Email: drprabudhgoel@gmail.com
}




\section{Animal Models of SARS-CoV-2: A Systematic Review}

\section{Abstract}

Background: The use of animal models for biomedical research provides us with a convenient and feasible route to establish causal relationships by recapitulating the temporal sequence of events in a controlled environment with a potential to manipulate the variables at multiple levels including genetic, protein, physiological or environmental.

Objectives: The current review was conducted to gain insights into various animal models for the SARS-CoV-2 virus.

Material and Methods: A literature review (PUBMED, PUBMED Central, PMC, Google Scholar, Google search engine) following the Preferred Reporting Items for Systematic Reviews and Meta-Analyses guidelines performed in early April 2020 revealed 9 articles of interest. Search terms included covid 19, covid-19, novel corona virus, SARS-CoV-2, animal models, experimental models, laboratory models \& covid 19 animal models.

Two independent reviewers extracted the data; the third reviewer was involved in case of discrepancy.

Results: SARS-CoV-2 shares an identical receptor binding domain with the SARS-CoV virus and has a superior binding affinity to the host ACE2. Based on this, the role of rhesus macaques, golden Syrian hamsters, transgenic hACE2 mice and ferrets as animal models have been studied. All four animals are susceptible to infection with SARS-CoV-2 with variable clinical presentation but universal recovery. The respiratory tract is primarily involved in all four models. Involvement of intestines was also seen in at least one study in each animal. Transfer to naïve animals in close contact has been documented in case of hamsters and ferrets. Seroconversion was documented in all although the role of convalescent sera was tested in hamsters only, with positive results though. Air-borne transmission was documented in ferrets and the possibility of feco-oral transmission was suggested for hamsters. The possibilities of recurrence and re-infection were ruled out by experiments upon the rhesus macaques. The fulfilment of Koch's postulates has been highlighted.

Discussion: The various studies available on animal models have been able to establish models of infection and transmission that recapitulate different aspects of disease in humans. 
However, the response between different animals and the same animal in different experiments is not completely coherent. Some of them do not manifest the disease clinically while others behave differently at molecular and immunological levels. Moreover, the physiology of these animals is not identical to human beings and the findings may not be extrapolated to human beings in an 'as-is' manner.

Conclusions: The review acknowledges the achievements made by these experiments in a short span of time and highlighted the urgent need for a deeper dive in search of a quintessential animal model which can be studied for efficacy and safety of newer drugs and vaccines before a make-shift from the petri-dish to the human body can be contemplated.

Keywords: animal models, experimental models, SARS-CoV-2, COVID-19, rhesus macaque, monkey, hamster, ferrets, transgenic mice 


\section{Introduction}

The virus has successfully invaded six continents, more than two hundred countries and 1.8 million patients resulting in a hundred-thousand deaths. The unpleasing and undesirable sequence of social distancing, travel restrictions and a universal lockdown, all resulting in severe disruption of global supply chain and economy started in late December 2019 [1]. A mysterious, SARS-like viral pneumonia was reported in few patients whom had a common history of exposure to the Huanan-Seafood-Wholesale-Market. It was on March 11, 2020 that the WHO escalated the disease-status to that of a pandemic. The etiological agent is a novel betacoronavirus, which has been nomenclated as the SARS-CoV-2 by the International Committee on Taxonomy of Viruses (ICTV) and the resulting disease is known as COVID-19 [2].

The unprecedented cross-border transmission of the disease has elicited unprecedented global public health response; a similar swiftness has been witnessed in the researchers' lobbies to gain insights into various disease mechanisms, novel vaccines and potential treatment options. The use of animal models for biological research facilitated by their remarkable anatomical and physiological similarity to humans provides us with a convenient and feasible route to establish causal relationships by recapitulating the temporal sequence of events in a controlled set-up with a potential to manipulate the variables at multiple levels including genetic, protein, physiological, behavioral or environmental.

\section{Objective of the Review}

The current review was conducted to gain insights into various animal models for the SARSCoV-2 virus and their implications for human-infection with the same virus.

\section{Material and Methods}

This systematic review was conducted according to the Preferred Reporting Items for Systematic Reviews and Meta-analysis (PRISMA) statement [3]. The review methods had been established prior to conduct of the review including stating the review question, search strategy, inclusion criteria for studies and formulation of study protocol.

None of the authors' had any conflict of interest and the study did not receive any funding. 
Studies (both randomized and non-randomized) discussing, describing or using an animal model of SARS-CoV-2 to highlight the clinical features, pathobiology of infection or modes of transmission following experimental inoculation with the virus were included in this review. Non-randomized studies were included for several reasons. Firstly, the virus has been recently identified permitting little time for animal research. Secondly, there is scarcity of published literature on the subject. However, whatever information is available is indispensable due to the pandemic-spread of the infection and urgent need for treatment modalities and vaccines alike.

Studies reporting in language other than English were however, excluded.

\section{Search Strategy}

Search for a Previous Review: Preliminary search for published literature was done to make sure that there is no published systematic review on this topic nor there is one on the way to completion.

All searches, screening of titles \& abstracts and study selection were done independently by two investigators (duplicate) and the results collated. Any discrepancy was resolved by verification with literature and consensus in the presence of third expert.

Literature Search: PUBMED/PUBMED Central/ PMC databases followed by Google Scholar/ Google search engine were interrogated using the strategies detailed in Figure 1. The final review is based on 9 studies [4-12].

\section{Data Extraction}

Extraction of data from the studies included for this review was performed by two independent investigators. Discrepancies were resolved by re-review of the respective study and consensus in presence of a third expert.

\section{Results}

The literature on COVID-19 is expanding rapidly (with an average of 500 publications per month over the past five months) and a large amount of research is being showcased ahead of peer review. Authors' search retrieved 2 publications which were available while they were under peer-review $[5,7]$. 


\section{Study Characteristics:}

The characteristics of studies included in this study have been summarized in Table 1.

\section{Choice of Animal Model for the SARS-CoV-2 virus}

In an attempt to address important issues related to the causative agent of this new disease, experts compared the genome sequences of this virus with other coronaviruses known to infect humans, the SARS-COV and the MERS-COV in particular. The representative genome of the SARS-CoV-2 virus was shown to be more homologous to SARS-CoV than MERS-CoV [13]. The S1 unit of S-protein in the coronal virus is responsible for binding to the host receptors through direct interaction of its C-terminal Receptor Binding Domain (RBD) with the host receptors [14]. The new virus shared an identical 3-D structure in the RBD domain with the SARS-CoV, thereby retaining similar van der Walls and electrostatic properties in the interaction interface [13]. Although four-of-five critical (for cross-species and human-tohuman transmission) amino acid residues at the receptor-complex interface were replaced in the SARS-CoV-2, the virus had a superior (to SARS-CoV) binding affinity to the human ACE2 [6]. The interface between the SARS-CoV-2 spike-glycoprotein-RBD is conducive to development of more hydrogen bonds with the ACE2.

The ACE2 receptors are distributed predominantly in the epithelial cells of the lungs and small intestine thereby strongly suggesting these routes as the portal of virus-entry into human beings [15].

\section{Monkeys as Animal Model for SARS-CoV-2}

The experimental details along-with clinical and pathological findings in rhesus macques have been summarized in Table 2 [4-5]. There were no obvious clinical manifestations except reduced appetite ( 1 of 6 ) and a delayed weight loss ( 2 of $6 ; 7 \%$ between $7-14 \mathrm{dpi}$ ). Viral RNA was demonstrated in oro-pharyngeal, nasal and anal swabs but not in the blood samples. The oro-pharyngeal swabs depicted two peaks in viral RNA count on 1 and 5 dpi which could be explained by experimental virus inoculation and viral replication respectively. The chest X-ray depicted expanding ground glass opacities over first six days of infection which corroborated with diffuse interstitial pneumonia upon histopathology. Whole genome sequence alignment analysis upon the virus re-isolated from the respiratory tract demonstrated $99.99 \%$ 
semblance to the original input virus samples. The generation of the serum antibodies was demonstrated with the plaque reduction neutralization test.

Relapse or reinfection [17-18] was studied in the 2 rhesus monkeys by re-inoculating them with the same virus 28 days after first exposure once they were confirmed to be cured (disappearance of symptoms, absence of radiological abnormalities and two negative reports of RT-PCR) [4]. Although there was a transient rise in body temperature, the naso-pharyngeal and anal swabs tested negative for the virus and the findings corroborated with histopathology of the lungs and other tissues. The antibody titers escalated by 2.5 times in one monkey. A third monkey was not re-exposed to the virus but followed up longitudinally and no relapse was observed during the two week after $28 \mathrm{dpi}$.

\section{Syrian Hamsters as Animal Models for SARS-CoV-2}

Schaecher et al. developed an immunocompromised Syrian hamster model for the SARS-CoV infection $[19,20]$; the SARS-CoV-2 exhibited even higher binding affinity with their ACE2 receptors [6].

Experimental studies (Table 2) have shown that the golden Syrian hamsters simulate SARSCoV-2 infection in humans with respect to clinical features, viral kinetics, histopathological changes and immune response. Clinical Features included progressive weight loss (more than $10 \%)$, lethargy, ruffled fur, hunch back posture and rapid breathing. Recovery was universal with no hamster mortality.

Viral load was higher in the upper and lower respiratory tract and the intestine. Although low levels of viral RNA were detected in several organs, viral $\mathrm{N}$ protein was detected only in the intestine. Histopathology of the respiratory tract, intestines, spleen, heart and lymph nodes (bronchial and mesenteric) was studied (Table 2).

Serum neutralizing antibodies were detected at $7 \mathrm{dpi}$. Passive immunization with early convalescent serum reduced the viral loads in the nasal turbinate and the lungs.

Transmission to naïve animals in close contact was demonstrated; surface-spike gene sequencing in virus samples from contact animals was similar to that of index animals (exception: H6554-mutation in one hamster).

Similar results have been replicated in another study [7], although, the histopathological damage was restricted to the respiratory tract sparing the other organs (Table 2). The fecal 
samples, however were positive for the viral RNA. Seroconversion happened at $14 \mathrm{dpi}$. The disease was transmitted to all hamsters in close contact who manifested similar clinical course, shed comparable load of viruses and presented a comparable immunological profile.

\section{The Humanized ACE2 (hACE2) mice as an Animal Model for SARS-CoV-2}

The humanized transgenic ACE2 mice is susceptible to SARS-CoV-2 infection [9] and the Koch's postulates [21] are fulfilled.

Clinical manifestations in mice are sparse (Table 2). Viral RNA was demonstrated in the lungs (peak at $3 \mathrm{dpi}$ ) and intestines only. Infectious virus could also be isolated from the lungs by Vero E6 cell culture but not the wild type mice and mock-infected hACE2 mice. Mounting of immune response was concomitant with identification of $\mathrm{MAC2}+$ macrophages, $\mathrm{CD} 3+\mathrm{T}$ lymphocytes and CD19+ B lymphocytes upon immunohistochemistry (IHC). Sero-conversion with S-protein specific IgG antibodies was demonstrated at $21 \mathrm{dpi}$. There was no diseaserelated mice-mortality.

The theory propounding the need for hACE2 in host cells for virus entry was supported by the co-localization of the SARS-CoV-2 S-protein and hACE2 receptor in the alveolar epithelial cells of the hACE2 mice upon IHC.

\section{Ferrets as Animal Model for the SARS-CoV-2}

Kim et al. [10] inoculated ferrets (Infected Ferrets) with SARS-CoV-2 and placed them with naïve ferrets: either co-housed (Direct Contact) or housed in a cage with permeable partition (Indirect Contact) separating them from infected ferrets (designed to study air-borne transmission).

Clinical features included elevated body temperature, reduced activity and occasional cough. Ferrets in Direct Contact showed similar clinical behavior supporting human-to-human transmission. They tested positive for viral RNA even before the infected ferrets were symptomatic explaining infectiousness of individuals during the incubation period while they are asymptomatic. Those in Indirect Contact were unaffected clinically.

Viral RNA was isolated from blood, nasal washes, saliva, urine and feces and multiple routes of viral transmission documented. The highest viral titers were recorded in the nasal washes in both the Infected Ferrets and those in Direct Contact. Copies of viral RNA were also isolated 
from the nasal swab and fecal specimens of two ferrets in Indirect Contact although they were clinically asymptomatic (air-borne transmission). Infectious virus was isolated from nasal washes (highest yield) and saliva of Infected Ferrets and only nasal wash of those in Direct Contact. The highest viral titers were recorded in nasal turbinate and lungs upon necropsy; infectious virus recovery was directly related to the viral RNA copy numbers.

Naïve ferrets could sustain infection by coming in contact with infected urine and feces.

Seroconversion was consistent with disappearance of clinical symptoms and disappearance of viral RNA. One of six ferrets in indirect contact group also tested positive for serum neutralizing antibody (air-borne transmission).

Shi et al. [12] also conducted experiments with the primary objective to study the susceptibility of ferrets, cats, dogs and other animals to SARS-CoV-2. The authors have incorporated the results of ferret-based experiments in this review for completing the context while the other animals have been excluded (Table 2). Viral replication in the upper respiratory tract of ferrets post intra-tracheal inoculation was documented for 8 days without causing significant disease or illness.

\section{Discussion}

The role of animals in biological research and medicine has been known for long. Although a matter of debate frequently, animals are indispensable to the understanding of disease pathobiology and in the pursuit for novel vaccines, drugs and therapies [22-23]. Basic research using animal models serves a multitude of functions such as, 1) mimic and assist in understanding the disease process in a controlled environment, 2) decipher the transmission routes of the infectious agents, 3 ) in vivo simulation of the immune response, 4) create an animal model to support active infection, shedding and transmission to sentinel animals, 5) development and assessment of diagnostic tools, 6) investigate newer vaccines and drugs for efficacy and safety prior to use in human beings, and 7) find out if the animals may serve as reservoirs of infection and perpetuate the virus over the years; does the pandemic reserve the potential to recur in a seasonal manner after the index event is contained.

The choice of animal models for the SARS-CoV-2 virus has been dictated by the presence of ACE2 receptors, similar to the SARS-CoV virus. Contrarily, the MERS-CoV virus attaches to the dipeptidyl peptidase-4 protein on the host cell through its surface spike (S) protein [24-25]. The binding affinity of ACE2 to the SARS-CoV-2, RBD is highest in rhesus macaque $(100 \%$ 
similarity in amino acid residues' alignment at the interface region with human beings) followed by the hamsters among all the species [6].

The SARS-CoV-2 was shown to infect and replicate in humanized transgenic hACE2 mice, ferrets, hamsters and several species of nonhuman primates such as the rhesus monkeys [26]. The virus however, replicates poorly in dogs, pigs, chickens and ducks [12].

The non-human primates (NHPs) including the monkeys have played a very vital role in biomedical research such as deep brain stimulation in the management of Parkinson's disease, treatment of bronchial asthma, development of transplant-related drugs and the use of incubators for premature infants, cancer, AIDS, and obesity/ diabetes[27-28]. Although 90\% of medical research is conducted on small animals such as mice, rats and other rodents and the NHPs account for less than $1 \%$, the utility and vitality of the non-human primates may be traced back to the close phylogenetic relationship with the Homo sapiens. The two also share some apsects of physiology, neuro-anatomy, reproduction, development, cognition and social complexity [29]. The utility of NHPs, however, is limited by the expertise and the scarce availability of the Biosafety Level-3 facilities to handle non-human primates. Besides, the increased likelihood that the primates experience pain and suffering in ways similar to the human being raises a lot of ethical issues with their use for biomedical research.

Studies [4-5] have shown that they are susceptible to infection with the SARS-CoV-2 virus. Although the clinical manifestations are scarce, a lot of similarities were documented between virus infection in monkeys and humans. The virus replication takes place not only in the upper and lower respiratory tract but in the gut as well similar to human beings. The virus isolated from the respiratory tract of the infected monkeys was identical (99.99\%) to the original virus, thereby satisfying the Koch's postulates in-principle [21]. Seroconversion with rising antibody titers signifies resolution of infection with development of immunity. Longterm follow-up (14 days beyond $28 \mathrm{dpi}$ ) was not suggestive of any recurrence. Re-exposure of the monkeys with the same virus at $28 \mathrm{dpi}$ could not re-establish infection; the immunity conferred by the antibodies was effective. There was no virus residue in the various body tissues after recovery from infection.

The study has offered the following suggestions, 1) the infection confers immunity postrecovery which is likely to be protective against future re-infections, 2) the convalescing patients are not expected to be contagious after mounting a strong antibody response, 3 ) the question as to how long will this immunity will be protective is yet to be answered since the 
study has a very brief follow-up and the numbers meagre. In case of the SARS virus, the immunity tends to wane off over a couple of years while it lasts for only a few weeks in case of some common cold viruses, 4) convalescent plasma therapy may be an option to rescue the critical cases, 5) development of antibody tests will be helpful in identifying individuals who have recovered from this infection such as in screening health-workers for immunity and to the epidemiologists in figuring out the hidden pattern of disease-spread, 7) the results are encouraging towards development of vaccines against this virus, and 8) the rhesus macaques may be useful in testing the safety and efficacy of vaccines, drugs and newer treatment strategies against this virus.

However, the 'as-is' applicability of these results to human being may be challenged by the observed rapid viral clearance mechanisms in the monkeys; human beings continue to be positive for the virus in the naso-pharyngeal swabs until upto 9-15 days after onset of symptoms (incubation period not be ignored) whereas the monkeys were cleared of infection on $15^{\text {th }}$ day post-infection.

Furthermore, the phenomenon of Antibody Dependent Enhancement which is a peculiar characteristic of the SARS-CoV virus was ruled out in context of the index virus [30]. Herein, the virus cannot re-infect the host cells by taking advantage of the host's humoral immune response to the initial infection.

Furthermore, the reason for repeat-positivity after discharge from the hospital cannot be reinfection, recurrence or relapse; the possibilities of false-negative results and a need to relook into the discharge criteria cannot be ignored.

The Syrian hamster (Mesocricetus auratus) has been used to study pathogenesis of human infections for more than six decades now. They are readily available, small in size, easy to handle, have a fast reproductive rate and mount an immune response similar to human beings [31]. The disease symptomatology and pathogenesis are also comparable. Hamsters have provided an effective platform in elucidation of various molecular-level developments in the immune system in response to viral (and other) infections [32-34]. Unlike the mouse models, they have fully functional human cytokines [35-36]. Hamsters are permissive for infection with other human respiratory viruses such as the influenza $A$ and other parainfluenza viruses.

Experimental infection with SARS-CoV-2 in golden Syrian hamsters have demonstrated the similarity to human infections in context of 1 ) route of entry of infection, 2) clinical features 
of disease although there was no mortality in hamsters while $5 \%$ of infections in human beings are lethal [37], 3) pathogenesis of the disease and viral kinetics including replication in the respiratory and digestive tracts, 4) histopathological damage to lungs (excluding the extensive apoptosis seen in hamsters) [38], 5) histopathological evidence of intestinal involvement consistent with the development of diarrhoea in 2-10\% cases of human infection [39-41], 6) focal myocardial degeneration consistent with occasional cardiac death in humans $[41], 7)$ lymphoid necrosis alongwith triggered cytokine expression consistent with the frequent lymphopenia (80\%) [37] and cytokine storm in human beings [42-45], 8) rapid clearance of the virus from lungs and spontaneous sero-conversion with appearance of neutralizing antibodies, 9) rapid transmission of the virus to those in close contact, and 10) higher load of infective virus in the nasal turbinate vis-à-vis lungs which explains the higher transmissibility of this virus as compared to the SARS-CoV (with comparable viral load between upper and lower respiratory tracts). Hamsters are known to be coprophagus and feco-oral transmission has been reserved as a possibility, and so may be the case in human beings. The two studies have also satisfied the Koch's postulates in principle. However, there is a striking discordance with regard to histopathology of extra-pulmonary tissues and seroconversion (7 vs $14 \mathrm{dpi}$ ). Based on these studies, hamsters have been suggested to be potential animal models to study the safety and efficacy of vaccines and convalescent plasma [46] or other novel therapeutic strategies.

The humanized ACE2 (hACE2) mice was developed in response to the 2002-03 global outbreak of SARS-CoV [47]. A vector carrying a human ACE2-coding sequence was introduced into the wild-type mice resulting in development of a successful hACE2 transgenic mouse strain. Expression is observed in airway epithelial cells where infection typically begins.

Bao et al. [9] have demonstrated the susceptibility to the virus, respiratory route of transmission, the need for ACE2 in the host cells to facilitate virus entry, virus kinetics, pulmonary pathology, presence of viral RNA in the intestines on $1 \mathrm{dpi}$, seroconversion with development of protective antibodies and fulfilment of the Koch's postulates.

Pathogenicity of SARS-CoV-2 is milder than that with SARS-CoV with sparing of extrapulmonary organ damage including brain, kidney, intestine, heart and liver. Similarly, cerebral vasculitis and hemorrhage were not observed with the new virus. These findings correlate with the relative clinical differences of the two infections in human beings. 
Although, organs other than the lungs and intestines did not document the presence of viral RNA or histopathological alterations, the role of humanized hACE2 transgenic mice may be vital to the development of vaccines and drugs against this virus. The Jackson Laboratory in Bar Harbor, Maine is one of the mouse-breeding facilities known to breed the hACE2 mice which were developed in response to the 2002-03 outbreak of SARS. Since no new cases were reported after 2003, the global interest in and funding for SARS were not encouraging; the lab did not preserve the hACE2 mouse colony. With the advent of the novel corona virus and renewed interest in this strain of transgenic mice, the laboratory is trying to establish the strain again with frozen mouse sperms. Currently, the laboratory is overwhelmed with orders for hACE2 mice [8].

The ferret (Mustela putorius furo) is the domesticated form of the European polecat and belongs to the same genus as the weasel, Mustela, in the family Mustelidae. They have a normal life span of 7-10 years [48]. In view of their small size (weight of an adult ferret is 700$1000 \mathrm{gm}$ for a female and 1400-2000 gm for a male) and relative familiarity to human anatomy, physiology and metabolism, the ferrets score over larger animal models such as the non-human primates.

Ferrets have a natural susceptibility to the human respiratory viruses and have been considered the ideal model for human influenza and proved to be useful in replicating the symptoms of several other viruses such as the respiratory syncytial virus and the SARS-CoV-1 [49-52]. This may partly be explained by their resemblance to human beings with regard to anatomic proportions of the upper and lower respiratory tracts, number of generations of the terminal bronchioles and the density of submucosal glands in the bronchial wall [51].

It has been shown that the SARS-CoV-2 recognizes ACE2 not only from humans but from ferrets and several other animal species (like pigs, cats, orangutans and monkeys) also, more so with similar efficiencies, because these ACE2 molecules are identical or similar in the critical virus-binding residues [53].

The ferret model which was initially developed to simulate the influenza virus infection [54] has been used in experiments with the SARS-CoV-2 virus to successfully demonstrate the Koch's postulates [21] and multiple aspects of SARS-CoV-2 infection including rapid viral replication, human-to-human transmission on close contact, air-borne transmission, multiple routes of virus shedding and transmissibility during the incubation period of the viral infection [10]. The shedding of virus through multiple portals including nasal washes, saliva, urine 
and feces renders the naïve hosts susceptible to rapid infection from infected hosts in close contact.

Of all the animal models studies till the time of conducting this review, air-borne transmission of this virus has only been demonstrated in the ferret-based experiments. Of the six ferrets housed in a cage with the infected ferrets but separate from them with a permeable partition, two of them tested positive for viral RNA in nasal swab and fecal specimen. One of them also produced neutralizing antibodies against the virus. This finding may have a bearing for the epidemiologist of today while trying to map the spreading patterns of the disease in the community.

Quality Assessment of the systematic review was done using the revised AMSTAR-2 which is based upon two tools, viz., Sack's Quality Assessment Checklist and Overview Quality Assessment Questionnaire [56]. The review is compliant with the following checklist items: the research question and inclusion criteria for the review includes the components of PICO (Item 1), establishment of review methods prior to conduct of the review (Item 2), description of the study design included in the review and explanation thereof (Item 3), use of comprehensive literature strategy including search in at least 2 databases, description of keywords or search strategy and justification of publication restriction (Item 4), execution of search and data extraction in duplicate (Item 5\&6), number (and not list) of studies excluded has been provided (Item 7), description of included studies in adequate detail including population, intervention, comparison and outcome (Item 8), discussion on heterogeneity in results wherever applicable (Item 14) and report upon authors' conflict of interest or source of funding (Item 16). However, the risk of bias assessment with allocation and blinding including publication bias was not done since the participants were non-humans (Items 9 \& 13, 15). Meta-analysis was not considered appropriate with the data extracted (Item 11 \& 12).

\section{Conclusions}

COVID-19 has spread to every corner of the globe within weeks and the menace is rising. Amidst the global response which could be deciphered to be a unique amalgamate of ultramodern (technology-based genome sequencing) with highly primitive strategy (of resorting to social distancing, quarantine and global lockdown as advocated during the $14^{\text {th }}$ century to fight the Black Death) [55], there cannot be a more urgent need for an animal model which 
helps us understand the in vivo characteristic of the SARS-CoV-2 virus by recapitulating the clinical symptomatology, transmission routes and pathobiology of the disease in human beings, thereby permitting testing of novel vaccines and pharmaceutical interventions.

The currently available studies on the role of various animals in the fight against the SARSCoV-2 have been trying to replicate the basic tenets of infection, transmission and immunological response in human against this virus. Not every animal which is available in the laboratory may be used; some are not susceptible to the virus, some do not show clinical signs of disease yet other behave differently at molecular and immunological levels.

There is a crying need for a deeper dive in search of a quintessential animal model which can be studied for efficacy and safety of newer drugs and vaccines before a make-shift from the petri-dish to the human body can be contemplated. 


\section{References}

1. Zhu, N, Zhang, D, Wang, W, Li, X, Yang, B, Song, J, Zhao, X, Huang, B, Shi, W, and Lu, R. A novel coronavirus from patients with pneumonia in China, 2019. N Engl J Med. 2020; 382:727-733.

2. ICTV, 2020. Naming the 2019 Coronavirus.

3. Liberati A, Altman DG, Tetzlaff J, Murlow C, Gøtzsche PC, et al. (2009) The PRISMA statement for reporting systematic reviews and meta-analyses of studies that evaluate health care interventions: explanation and elaboration. Ital J Public Health 4: 354-91.

4. Bao L, Deng W, Gao H, Xiao C, Liu J, Xue J et al. Reinfection could not occur in SARS-CoV-2 infected rhesus macaques. < https://www.biorxiv.org/content/10.1101/2020.03.13.990226v1

5. Shan C, Yao Y, Yang X, Zhou Y, Wu J, Gao G, et al. Infection with Novel Coronavirus (SRS-CoV-2) Causes Pneumonia in the Rhesus Macaques. < https://www.researchsquare.com/article/rs-15756/v1 >.

6. Chan JF, Zhang AJ, Yuan S, Poon VK, Chan CC, Lee AC, Chan WM, Fan Z, Tsoi HW, Wen L, Liang R, Cao J, Chen Y, Tang K, Luo C, Cai JP, Kok KH, Chu H, Chan KH, Sridhar S, Chen Z, Chen H, To KK, Yuen KY. Simulation of the clinical and pathological manifestations of Coronavirus Disease 2019 (COVID-19) in golden Syrian hamster model: implications for disease pathogenesis and transmissibility. Clin Infect Dis. 2020 Mar 26. pii: ciaa325. doi: 10.1093/cid/ciaa325.

7. Sia SF, Yan L, Chin AW, Fung K, Poon LL, Nicholls JM, et al. Pathogenesis and transmission of SARSCoV-2 virus in golden Syrian hamsters. < https://www.researchsquare.com/article/rs-20774/v1 >.

8. Callaway E. Labs rush to study coronavirus in transgenic animals - some are in short supply. Nature. 2020 Mar;579(7798):183.

9. Bao L, Deng W, Huang B, Gao H, Liu J, Ren L, et al. The Pathogenicity of SARS-CoV-1 2 in hACE2 Transgenic Mice. < https://www.biorxiv.org/content/10.1101/2020.02.07.939389v3>.

10. Kim YI, Kim SG, Kim SM, Kim EH, Park SJ, Yu KM, Chang JH, Kim EJ, Lee S, Casel MAB, Um J, Song MS, Jeong HW, Lai VD, Kim Y, Chin BS, Park JS, Chung KH, Foo SS, Poo H, Mo IP, Lee OJ, Webby RJ, Jung JU, Choi YK. Infection and Rapid Transmission of SARS-CoV-2 in Ferrets. Cell Host Microbe. 2020 Apr 5. pii:S1931-3128(20)30187-6. doi: 10.1016/j.chom.2020.03.023.

11. Cyranoski D. This scientist hopes to test coronavirus drugs on animals in locked-down Wuhan. Nature. 2020 Jan;577(7792):607.

12. Shi J, Wen Z, Zhong G, Yang H, Wang C, Huang B, et al. Susceptibility of ferrets, cats, dogs and other domesticated animals to SARS-coronavirus 2. Science. 2020; 10.1126/science.abb7015.

13. Xu X, Chen P, Wang J, Feng J, Zhou H, Li X, Zhong W, Hao P. Evolution of the novel coronavirus from the ongoing Wuhan outbreak and modeling of its spike protein for risk of human transmission. Sci China Life Sci. 2020 Mar;63(3):457-460.

14. Li F. Evidence for a common evolutionary origin of coronavirus spike protein receptor-binding subunits. J Virol. 2012 Mar;86(5):2856-8.

15. Hamming, et al. Tissue distribution of ACE2 protein, the functional receptor for SARS coronavirus. A first step in understanding SARS pathogenesis. J Pathol 203, 631-637, doi:10.1002/path.1570 (2004).

16. Zhou, P. et al. A pneumonia outbreak associated with a new coronavirus of probable bat origin. Nature, doi:10.1038/s41586-020-2012-7 (2020). 
17. Lan L, Xu D, Ye G, Xia C, Wang S, Li Y, Xu H. Positive RT-PCR Test Results in Patients Recovered From COVID-19. JAMA. 2020 Feb 27. doi: 10.1001/jama.2020.2783.

18. Zhou L, Liu Q, Liu HG. Novel coronavirus pneumonia patients' recurrence after discharge: Causes 143 Analysis and treatment strategies. Chin J Tubere Respir Dis 2020;43.

19. de Wit, et al. The Middle East respiratory syndrome coronavirus (MERS-CoV) does not replicate in Syrian hamsters. PLoS One 8, e69127, doi:10.1371/journal.pone.0069127 (2013).

20. Schaecher SR, Stabenow J, Oberle C, Schriewer J, Buller RM, Sagartz JE, et al. . An immunosuppressed Syrian golden hamster model for SARS-CoV infection. Virology. (2008) 380:312-21.

21. Rivers TM. Viruses and Koch's Postulates. J Bacteriol. 1937 Jan;33(1):1-12.

22. Gong S, Bao L. The battle against SARS and MERS coronaviruses: Researvoirs and Animal Models. Animal Model Exp Med. 2018; 1:125-133.

23. Vergara-Alert J, Vidal E, Bensaid. A, Segales J. Searching for animal models and potential target species for emerging pathogesn: Experience gained form Middle East Respiratory Sundrome (MERS) coronavirus. One. Health. 2017; 3:34-40.

24. Xia S, Liu Q, Wang Q, Sun Z, Su S, Du L, Ying T, Lu L, Jiang S. Middle East respiratory syndrome coronavirus (MERS-CoV) entry inhibitors targeting spike protein. Virus Research. 2014;194:200-210.

25. Lu G, Hu Y, Wang Q, Qi J, Gao F, Li Y, et al. Molecular basis of binding between novel human coronavirus MERS-CoV and its receptor CD26. Nature. 2013; 500:227-32.

26. McCray PB Jr, Pewe L, Wohlford-Lenane C, Hickey M, Manzel L, Shi L, Netland J, Jia HP, Halabi C, Sigmund CD, Meyerholz DK, Kirby P, Look DC, Perlman S. Lethal infection of K18-hACE2 mice infected with severe acute respiratory syndrome coronavirus. J Virol. 2007 Jan;81(2):813-21.

27. Phillips KA, Bales KL, Capitanio JP, Conley A, Czoty PW, 't Hart BA, Hopkins WD, Hu SL, Miller LA, Nader MA, Nathanielsz PW, Rogers J, Shively CA, Voytko ML. Why primate models matter. Am J Primatol. 2014 Sep;76(9):801-27.

28. Friedman H, Ator N, Haigwood N, Newsome W, Allan JS, Golos TG, Kordower JH, Shade RE, Goldberg ME, Bailey MR, Bianchi P. The critical role of non-human primates in medical research. Pathog Immun. $2017 ; 2: 352-365$.

29. Seok J, Warren HS, Cuenca AG, Mindrinos MN, Baker HV, Xu W, Richards DR, McDonald-Smith GP, Gao $\mathrm{H}$, Hennessy L, et al. Genomic responses in mouse models poorly mimic human inflammatory diseases. Proceedings of the National Academy of Sciences. $2013 \mathrm{~b}$.

30. Wang SF, Tseng S-P, Yen C-H, et al. Antibody-dependent SARS coronavirus infection is mediated 147 by antibodies against spike proteins. Biochemical \& Biophysical Research Communications;451:208-14.

31. Miao J, Chard LS, Wang Z, Wang Y. Syrian Hamster as an Animal Model for the Study on Infectious Diseases. Front Immunol. 2019; 10:2329.

32. Ogg M, Jonsson CB, Camp JV, Hooper JW. Ribavirin protects Syrian hamsters against lethal hantavirus pulmonary syndrome-after intranasal exposure to Andes virus. Viruses. (2013) 5:2704-20.

33. Prescott J, DeBuysscher BL, Brown KS, Feldmann H. Long-term single-dose efficacy of a vesicular stomatitis virus-based Andes virus vaccine in Syrian hamsters. Viruses. (2014) 6:516-23.

34. $\mathrm{Zu}$ Rhein GM. Studies of JC virus-induced nervous system tumors in the Syrian hamster: a review. Prog Clin Biol Res. (1983) 105:205-21. 
35. Cho SA, Park JH, Seok SH, Juhn JH, Kim SJ, Ji HJ, et al. . Effect of granulocyte macrophage-colony stimulating factor (GM-CSF) on 5-FU-induced ulcerative mucositis in hamster buccal pouches. Exp Toxicol Pathol. (2006) 57:321-8.

36. Wang P, Li X, Wang J, Gao D, Li Y, Li H, et al. . Re-designing Interleukin-12 to enhance its safety and potential as an anti-tumor immunotherapeutic agent. Nat Commun. (2017) 8:1395. 10.1038/s41467-01701385-8.

37. Guan WJ, Ni ZY, Hu Y, Liang WH, Ou CQ, He JX, Liu L, Shan H, Lei CL, Hui DSC, Du B, Li LJ, Zeng G, Yuen KY, Chen RC, Tang CL, Wang T, Chen PY, Xiang J, Li SY, Wang JL, Liang ZJ, Peng YX, Wei L, Liu Y, Hu YH, Peng P, Wang JM, Liu JY, Chen Z, Li G, Zheng ZJ, Qiu SQ, Luo J, Ye CJ, Zhu SY, Zhong NS; China Medical Treatment Expert Group for Covid-19. Clinical Characteristics of Coronavirus Disease 2019 in China. N Engl J Med. 2020 Feb 28. doi: 10.1056/NEJMoa2002032.

38. Xu Z, Shi L, Wang Y, Zhang J, Huang L, Zhang C, Liu S, Zhao P, Liu H, Zhu L, Tai Y, Bai C, Gao T, Song J, Xia P, Dong J, Zhao J, Wang FS. Pathological findings of COVID-19 associated with acute respiratory distress syndrome. Lancet Respir Med. 2020 Apr;8(4):420-422. doi: 10.1016/S2213-2600(20)30076-X.

39. Wang D, Hu B, Hu C, Zhu F, Liu X, Zhang J, Wang B, Xiang H, Cheng Z, Xiong Y, Zhao Y, Li Y, Wang X, Peng Z. Clinical Characteristics of 138 Hospitalized Patients With 2019 Novel Coronavirus-Infected Pneumonia in Wuhan, China. JAMA. 2020 Feb 7. doi: 10.1001/jama.2020.1585.

40. Pan Y, Zhang D, Yang P, Poon LLM, Wang Q. Viral load of SARS-CoV-2 in clinical samples. Lancet Infect Dis. 2020 Apr;20(4):411-412. doi:10.1016/S1473-3099(20)30113-4.

41. Chen N, Zhou M, Dong X, Qu J, Gong F, Han Y, Qiu Y, Wang J, Liu Y, Wei Y, Xia J, Yu T, Zhang X, Zhang L. Epidemiological and clinical characteristics of 99 cases of 2019 novel coronavirus pneumonia in Wuhan, China: a descriptive study. Lancet. 2020 Feb 15;395(10223):507-513. doi: 10.1016/S01406736(20)30211-7.

42. Ruan Q, Yang K, Wang W, Jiang L, Song J. Clinical predictors of mortality due to COVID-19 based on an analysis of data of 150 patients from Wuhan, China. Intensive Care Med. 2020 Mar 3. doi: 10.1007/s00134020-05991-x.

43. Cheng VC, Lau SK, Woo PC, Yuen KY. Severe acute respiratory syndrome coronavirus as an agent of emerging and reemerging infection. Clin Microbiol Rev 2007; 20:660-94.

44. Chan JF, Lau SK, To KK, Cheng VC, Woo PC, Yuen KY. Middle East respiratory syndrome coronavirus: another zoonotic betacoronavirus causing SARS-like disease. Clin Microbiol Rev 2015; 28: 465-522.

45. Cheng VC, To KK, Tse H, Hung IF, Yuen KY. Two years after pandemic influenza A/2009/H1N1: what have we learned? Clin Microbiol Rev 2012; 25: 223-263.

46. Liu L, Wei Q, Lin Q, Fang J, Wang H, Kwok H, Tang H, Nishiura K, Peng J, Tan Z, Wu T, Cheung KW, Chan KH, Alvarez X, Qin C, Lackner A, Perlman S, Yuen KY, Chen Z. Anti-spike IgG causes severe acute lung injury by skewing macrophage responses during acute SARS-CoV infection. JCI Insight. 2019 Feb $21 ; 4(4)$.

47. McCray PB Jr, Pewe L, Wohlford-Lenane C, Hickey M, Manzel L, Shi L, Netland J, Jia HP, Halabi C, Sigmund CD, Meyerholz DK, Kirby P, Look DC, Perlman S. Lethal infection of K18-hACE2 mice infected with severe acute respiratory syndrome coronavirus. J Virol. 2007 Jan;81(2):813-21.

48. https://en.wikipedia.org/wiki/Ferret, accessed on April 10, 2020. 
49. Capraro GA, Johnson JB, Kock ND, Parks GD. Virus growth and antibody responses following respiratory tract infection of ferrets and mice with WT and P/V mutants of the paramyxovirus Simian Virus 5. Virology. 2008; 376(2):416-28.

50. Chan KF, Carolan LA, Korenkov D, Druce J, McCaw J, Reading PC, Barr IG, Laurie KL. Investigating Viral Interference Between Influenza A Virus and Human Respiratory Syncytial Virus in a Ferret Model of Infection. J Infect Dis. 2018; 218(3):406-417.

51. Enkirch T, von Messling V. Ferret models of viral pathogenesis. Virology. 2015; 479-480:259-70.

52. Park SJ, Kim EH, Kwon HI, Song MS, Kim SM, Kim YI, Si YJ, Lee IW, Nguyen HD, Shin OS, Kim CJ, Choi YK. Altered virulence of Highly Pathogenic Avian Influenza (HPAI) H5N8 reassortant viruses in mammalian models. Virulence. 2018; 9(1):133-148.

53. Wan, Y, Shang, J, Graham, R, Baric, RS, and Li, F. Receptor recognition by novel coronavirus from Wuhan: An analysis based on decade-long structural studies of SARS. J Virol. 2020; 94(7). pii: e00127-20.

54. Park SJ, Kim EH, Kwon HI, Song MS, Kim SM, Kim YI, Si YJ, Lee IW, Nguyen HD, Shin OS, Kim CJ, Choi YK. Altered virulence of Highly Pathogenic Avian Influenza (HPAI) H5N8 reassortant viruses in mammalian models. Virulence. 2018 Jan 1;9(1):133-148.

55. https://www.history.com/news/quarantine-black-death-medieval, accessed on April 11, 2020.

56. https://amstar.ca/docs/AMSTAR-2.pdf, last accessed on May 15, 2020. 


\section{PRISMA Flow Diagram}

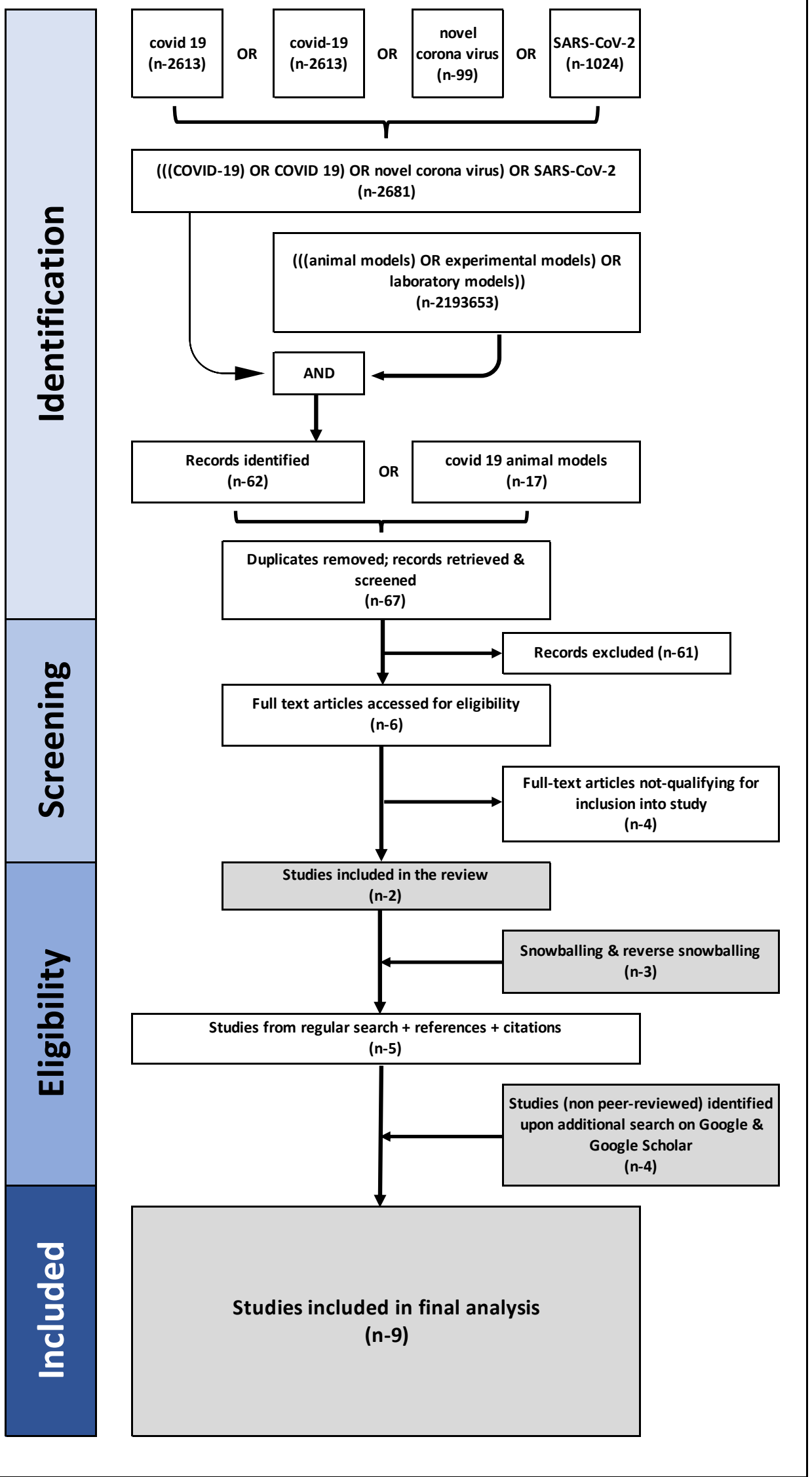


Table 1: Characteristics of Studies included for the Review

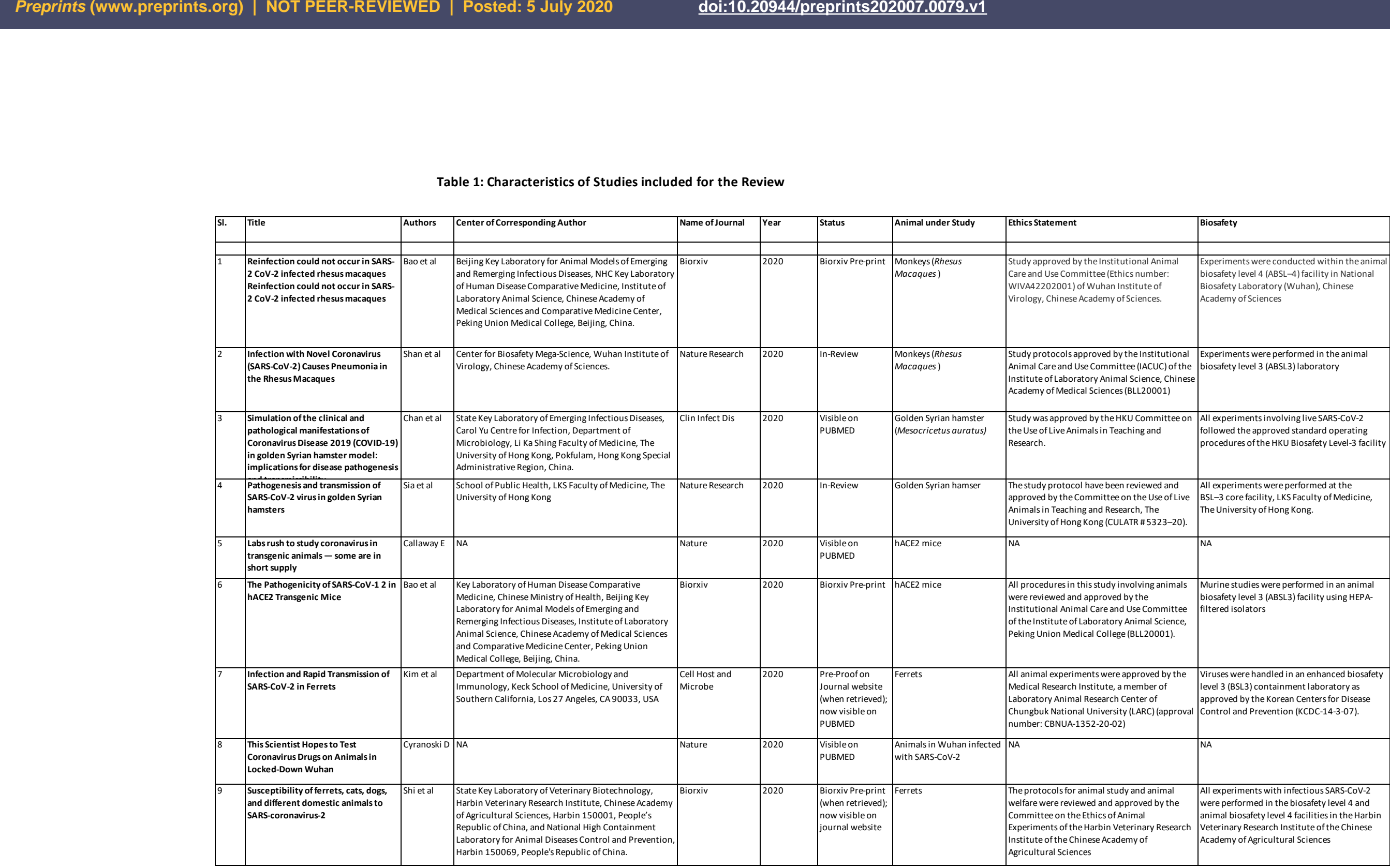


Table 2: Detailed Summary of the Studies included in the Review

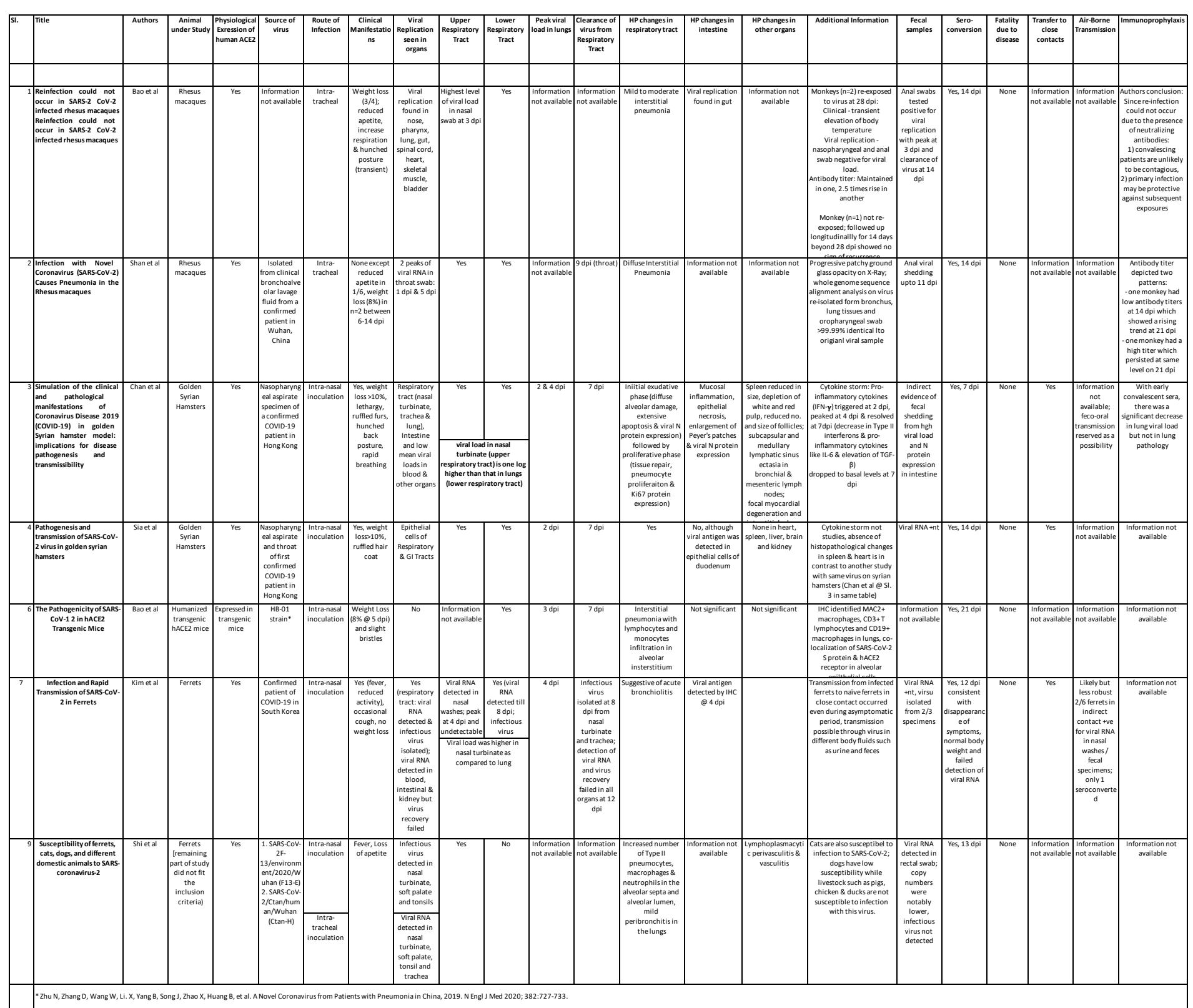

